\title{
Alcohol withdrawal delirium - diagnosis, course and treatment
}

\author{
Barbora Mainerova ${ }^{a}$, Jan Prasko ${ }^{a}$, Klara Latalovaa ${ }^{a}$ Karel Axmann ${ }^{b}$, Monika Cerna $^{a}$, Rostislav Horacekc, Romana Bradacova ${ }^{a}$
}

Objective. Delirium tremens represents the most severe complication of alcohol withdrawal syndrome and, in its complications, significantly increases the morbidity and mortality of patients. Alcohol withdrawal delirium is characterized by features of alcohol withdrawal itself (tremor, sweating, hypertension, tachycardia etc.) together with general delirious symptoms such as clouded consciousness, disorientation, disturbed circadian rhythms, thought processe and sensory disturbances, all of them fluctuating in time. The treatment combines a supportive and symptomatic approach. Benzodiazepines in supramaximal doses are usually used as drugs of choice but in some countries such as the Czech Republic or Germany, clomethiazole is frequently used as well.

Method. A computer search of the all the literature published between 1966 and December 2012 was accomplished on MEDLINE and Web of Science with the key words "delirium tremens", "alcohol withdrawal", "treatment" and "pharmacotherapy". There were no language or time limits applied.

Conclusions. When not early recognized and treated adequately, delirium tremens may result in death due to malignant arrhythmia, respiratory arrest, sepsis, severe electrolyte disturbance or prolonged seizures and subsequent trauma. Owing to these possible fatalities and other severe unexpected complications, delirium tremens should be managed at an ICU or wards ensuring vital signs monitoring. In symptomatic treatment, high doses of benzodiazepines, especially lorazepam, diazepam and oxazepam are considered the gold standard drugs. Supportive therapy is also of great importance.

Key words: delirium tremens, alcohol withdrawal, treatment, pharmacotherapy, benzodiazepines

Received: February 21, 2013; Accepted with revision: November 21, 2013; Available online: December 11, 2013 http://dx.doi.org/10.5507/bp.2013.089

${ }^{a}$ Department of Psychiatry, Faculty of Medicine and Dentistry, Palacky University Olomouc and University Hospital Olomouc, Czech Republic ${ }^{b}$ Department of Anesthesiology and Intensive Care Medicine, University Hospital Olomouc 'Department of Intensive Surgical Care, University Hospital Olomouc

Corresponding author: Jan Prasko, e-mail: praskojan@seznam.cz

\section{INTRODUCTION}

Due to historical and social factors, alcohol does not usually belong to the group of illicit substances. This fact makes it one of the most common drugs of abuse with enormous social and economic impacts worldwide. Alcohol plays a main role in substance use disorders and alcohol abuse represents a significant issue with increasing morbidity and mortality in the population ${ }^{1-6}$.

Among these complications, acute withdrawal syndrome, or withdrawal delirium, may occur when blood or tissue alcohol levels decline after intake reduction or a modest period of cessation or dose reduction. Alcohol withdrawal delirium always represents one of the psychiatric emergencies. The symptoms of alcohol withdrawal delirium were first described by Samuel Pearson in 1813 as a "brain fever". The term "delirium tremens" was introduced the same year by British physician Thomas Sutton in his book "Tracts on delirium tremens, on peritonitis, and on some other inflammatory affections, and on gout".

\section{METHOD}

A computer search of the all the literature published between 1966 and December 2012 was accomplished on MEDLINE and Web of Science with the key words "de- lirium tremens”, "alcohol withdrawal”, "treatment” and "pharmacotherapy". There were no language or time limits applied. The obtained list of references to the articles was manually re-examined to find additional articles.

\section{CLINICAL PICTURE}

Alcohol withdrawal syndrome appears after a significant reduction or complete discontinuation of alcohol consumption in patients suffering from alcohol dependence. The most severe complication of alcohol withdrawal syndrome is alcohol withdrawal delirium (delirium tremens), which may be preceded or complicated by seizures. The withdrawal symptoms are caused by specific changes in brain neurophysiology after various periods of (usually heavy) drinking ${ }^{7}$. Alcohol withdrawal syndrome represents a group of certain symptoms that arise usually 1-3 days after the last $\mathrm{drink}^{8}$. Sometimes the symptoms are already present when the alcohol blood level is above $0(0.5 \%$ or even more $)$. In the mild form of the syndrome, tremor, hyperactivity, anxiety, tachycardia, sweating and sleep disturbances are present. In severe alcohol withdrawal, especially when untreated, hallucinations, seizures and delirium may occur. Even with the proper treatment, delirium tremens may be a life-threatening condition in $1-5 \%$ of patients ${ }^{9-12}$. 
Delirium is a global confusional state (in some countries, the term "qualitative disturbance of consciousness" is used). It may present as a hyperactive state with increased arousal and psychomotor activity or agitation with substantial vegetative and other psychological symptoms (disorientation, illusions, hallucinations, delusions, affective instability, irritability, attention disturbance, combativeness), typical for alcohol withdrawal delirium as described in ICD-10 criteria. In some patients, delirium manifests as a hypoactive state with decreased arousal and psychomotor activity. Although this picture is rare in alcohol withdrawal delirium, it is associated with worse prognosis, delayed diagnosis and treatment and later complications. In the remaining patients, a mixed type of delirium with fluctuations between the two types is present. Complete or fragmentary amnesia is also among the delirium symptoms.

Somatic symptoms are important components of delirium. They are present at two levels: vegetative, comprising tachycardia, blood pressure fluctuations, body temperature increase, sweating, mydriasis, hyperhydrosis, nausea, vomiting and diarrhea and accompanying CNS symptoms, comprising tremor, ataxia, dysarthria, dysphagia, agnosia, aphasia, myoclonus and epileptic paroxysms (usually generalized tonic-clonic convulsions).

Apart from DT, here are other psychiatric problems associated with withdrawal such as acute alcohol halucinosis.

\section{DIAGNOSIS}

Contemporary diagnostic criteria for alcohol withdrawal delirium cover qualitative disturbance of consciousness, cognitive dysfunction fluctuating in time or rapidly developing perceptual disturbances. All the symptoms must emerge during, or shortly after, heavy alcohol intake cessation.

According to the ICD-10, alcohol withdrawal delirium (F10.4) is defined as alcohol withdrawal state (F10.3) complicated by delirium (F05.-); seizures may also appear.

\section{X.3 - Withdrawal state, general criteria}

G1. Clear evidence of recent cessation or reduction of substance use after repeated and usually prolonged and/ or high-dose use of that substance.

G2. Symptoms and signs compatible with the known features of a withdrawal state from the particular substance or substances.

G3. Not accounted for by a medical disorder unrelated to substance use and not better accounted for by another mental or behavioral disorder.

\section{Alcohol withdrawal syndrome (F10.3)}

A. The general withdrawal criteria must be met.

B. At least 3 of the following:

1) tremor of the tongue, eyelids or outstretched arms;

2) sweating;

3) nausea, retching or vomiting;
4) tachycardia or hypertension;

5) psychomotor hyperactivity;

6) headache;

7) insomnia;

8) malaise or weakness;

9) transitory visual, auditory or tactile hallucinations or illusions;

10) seizures - generalized, tonic-clonic.

Delirium other than induced by alcohol or other psychoactive substances (F05.-)

A. Clouding of consciousness, i.e. reduced clarity of awareness of the environment, with reduced ability to focus, sustain or shift attention.

B. Disturbance of cognition, manifest by both:

(1) impairment of immediate recall and recent memory, with relatively intact remote memory;

(2) disorientation in time, place or person.

C. At least one of the following psychomotor disturbances:

(1) rapid, unpredictable shifts from hypo-activity to hyper-activity;

(2) increased reaction time;

(3) increased or decreased flow of speech;

(4) enhanced startle reaction.

D. Disturbance of sleep or the sleep-wake cycle, manifest by at least one of the following:

(1) insomnia, which in severe cases may involve total sleep loss, with or without daytime drowsiness, or reversal of the sleep-wake cycle;

(2) nocturnal worsening of symptoms;

(3) disturbing dreams and nightmares which may continue as hallucinations or illusions after awakening.

E. Rapid onset and fluctuations of the symptoms over the course of the day.

\section{PREVALENCE}

Approximately $16-26 \%$ of hospitalized patients have problems with alcohol dependence ${ }^{6}$. Withdrawal symptoms arise in $31 \%$ of trauma patients and in $16 \%$ of surgery patients in the postoperative period ${ }^{13-15}$.

At psychiatric wards in Germany, the annual prevalence of the diagnosis of delirium in alcohol-dependent patients was $0.6-0.7 \%$ or $4.9-7.4$ (ref. $^{16,17}$ ). At departments specializing in alcohol dependence treatment, the rate of delirium tremens was $5-11 \%$ (ref. $^{18,19}$ ).

In the Finnish population, the lifetime prevalence of alcohol-induced delirium was $0.18 \%$ (95\% CI 0.11-0.32\%) $\left(\right.$ ref. $\left.{ }^{20}\right)$. Other reviews showed the expectation of experiencing withdrawal delirium to be $4-15 \%$ for alcoholdependent individuals ${ }^{21,22}$.

Delirium develops in 5-20\% of patients treated for alcohol withdrawal syndrome ${ }^{10,11,23,24}$, with the rates varying from study to study from $1.25 \%$ to $33 \%$. 


\section{ETIOPATHOGENESIS}

The etiopathogenesis of alcohol withdrawal delirium will be mentioned briefly in this paper. Although delirium tremens is known to complicate an alcohol withdrawal state, there is no clear explanation of the fact that only $5-10 \%$ of withdrawals result in delirium ${ }^{25}$. The kindling effect is considered to play an important role in delirium development ${ }^{26-28}$. According to Ballenger and Post $^{29}$, kindling is responsible for certain graduation of withdrawal symptoms as a function of number of previous abstinence and intoxication episodes, resulting in lower seizure threshold and CNS excitability. This represents a stimulus for the kindling process in subcortical structures (the limbic system, hypothalamus and thalamus). The more often withdrawal episodes repeat, the more severe they become and may result in seizures and delirium tremens.

Chronic exposure to ethanol results in down-regulation of inhibitory gamma-aminobutyric acid (GABA) receptors in the CNS. On the other hand, excitatory N-methyl-Daspartate (NMDA) glutamate receptors are up-regulated in alcohol dependence. Abrupt cessation of alcohol intake results in withdrawal syndrome when this neuroadaptation is unmasked ${ }^{31}$. The role of benzodiazepines in alcohol detoxification is to re-establish the balance and suppress the predominance of glutamate by enhancing GABA transmission. In the United States, benzodiazepines are recommended in moderate to severe alcohol withdrawal and delirium tremens management ${ }^{11}$.

The neurophysiology of GABA and glutamate transmission is identical in alcohol withdrawal delirium. An increase in noradrenaline and dopamine neurotransmission was discovered as well. Neurotoxicity, damage of CNS neurons, arousal and sympathetic activity increase resulting from oxidative stress and increased intracellular calcium influx represent common findings in delirium tremens. Benzodiazepine and clomethiazole use is also in accordance with the GABA-ergic model and has a positive influence on withdrawal and epileptic seizures.

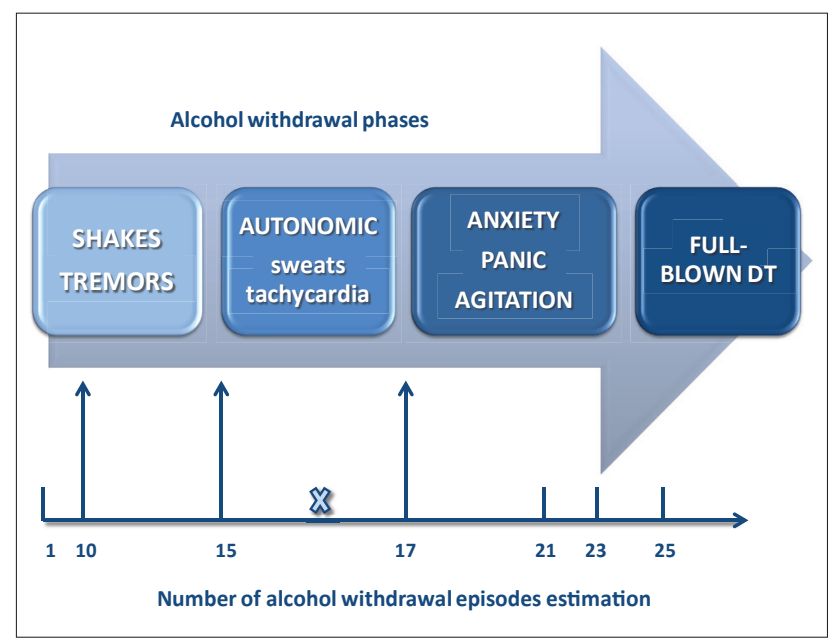

Fig. 1. The kindling phenomenon, adapted from Post 2002 $\left(\right.$ ref. $\left.{ }^{30}\right)$.
Delirium tremens usually develops in individuals with a history of long-term and heavy drinking ${ }^{19,20}$.

\section{COURSE}

Delirium usually develops within $24-72 \mathrm{~h}$ as an acute or subacute complication of withdrawal syndrome ${ }^{32-37}$.

Throughout the day, the fluctuation of symptoms is typical with worsening in the evening and at night (disturbance of circadian rhythm or its inversion). The symptoms usually slowly subside within 1-7 days. The symptoms of withdrawal itself (as defined in the ICD-10) are often still present several days after the delirious features have fully subsided.

Despite complete or partial amnesia, the experience of delirium is traumatizing for the patient and may lead to long-term mental disorders interfering with full recovery.

\section{COMPLICATIONS OF DELIRIUM TREMENS}

Delirious patients have high morbidity and mortality rates. Mortality in the next 8 years after an episode of delirium tremens was $30.8 \%(\mathrm{HR}=1.38,95 \%$ CI $0.43-4.48)$, which is comparable with patients suffering from severe malignant diseases ${ }^{20,38}$.

Without proper management, mortality may range from $5 \%$ to $15 \%$ or even $20 \%$ (ref. $^{23,39}$ ). When treated appropriately (benzodiazepines) and detected early, the mortality should not exceed $1 \%$ (ref. ${ }^{11,40}$ ).

Delirium tremens may be complicated by several severe or life-threatening conditions. When diagnosed and managed insufficiently, the morbidity and mortality rates increase, hospitalization prolongs and complications such as status epilepticus, coma or other severe psychiatric disorders such as Wernicke-Korsakoff syndrome, central pontine myelinolysis, chronic alcohol halucinosis or even dementia may develop.

As the most frequent complications, injuries (bed falls, seizures) such as fractures, intracranial hemorrhage, hypokalemia, hypomagnesemia, upper gastrointestinal bleeding, pneumonia, vomiting, aspiration with pneumonia, respiratory arrest, arrhythmias, sepsis, bed sores or death may emerge; also possible escape from the ward may result in an injury or unintentional self-injury ${ }^{32,33,36}$.

\section{TREATMENT}

The management of delirium tremens represents a multidisciplinary (psychiatry, neurology, intensive and internal medicine professionals etc.) and comprehensive approach, with nurses and the patient's family being involved as well. The treatment is provided at six different levels ${ }^{41}$.

\section{Preventive measures}

According to clinical experience, thorough monitoring and prompt treatment of the withdrawal syndrome is 
the best way of preventing severe complication such as delirium tremens ${ }^{42}$.

Many studies focus on severe alcohol withdrawal syndrome from the point of view of possible risk factors. A previous episode of delirium and/or seizures during withdrawal in the patient's history seems to be the greatest risk factor/ predictor ${ }^{10,23,24,43,44}$. Other risk factors/predictors may be concurrent medical illness or infectious diseases ${ }^{10,19,40,43,45}$. According to other studies, tachycardia of more than 100 or 120 beats per minute and hypertension - systolic blood pressure over $145 \mathrm{mmHg}$ - above may represent potential risk factors/predictors ${ }^{23,43,44}$.

There are several laboratory features showing a potential risk of delirium such as low levels of serum potassium although this finding could not be replicated in a study using subsequent multivariate analysis ${ }^{23,46,47}$. According to studies using specially designed rating scales, elevated liver enzymes - alanine aminotransferase (ALT), aspartate aminotransferase (AST) and gamma-glutamyltransferase (GGT) - or carbohydrate-deficient transferrin (CDT) and mean corpuscular volume (MCV) can predict more severe alcohol withdrawal ${ }^{48}$. Brathen et al. described significant relation of elevated levels of ALT, AST, ALT/AST ratio, GGT and CDT and alcohol-related seizures, with CDT being the best single marker. Low sensitivity of all these laboratory parameters impede their routine clinical use in predicting severe withdrawal ${ }^{48,49}$.

A study of 182 alcohol-dependent individuals showed significant association of early emergency management and serum ALT level above 1.5-fold the upper limit and severe withdrawal symptoms ${ }^{21}$. In other studies, the frequency of thrombocytopenia or functional changes of platelets was much higher in patients developing delirium or seizures ${ }^{12,50}$. Some studies show some connection between brain serotonin dysregulation due to monoamino oxidase (MAO) inhibion and DT development in alcohol dependent individuals ${ }^{50,51}$. Changes in liver enzymes and CDT in delirious patients may, as parallel phenomena, show excessive alcohol intake. Also plasma levels of the methionine metabolite homocysteine are significantly elevated in individuals with delirium tremens as compared to uncomplicated withdrawal. Homocysteine elevation was found to be connected with withdrawal seizure acitivity $^{52,53}$.

In case of a high risk of alcohol withdrawal delirium, the use of benzodiazepines for preventive purposes may be reasonable.

There is no evidence that administration of ethanol to delirious patients or those at risk for delirium is superior or even equal in effect or side effects to benzodiazepines $^{54,55}$.

Patients fearing the withdrawal symptoms, can lose adherence to the treatment of their dependence when the withdrawal symptom control and management are not adequate at the very beginning ${ }^{9,56,57}$. A proper detoxification program and withdrawal management can alleviate future severity of subsequent attacks of the alcohol withdrawal syndrome and help to increase the motivation for comprehensive treatment and abstinence ${ }^{9,58}$. From the pharmaco- logical point of view, benzodiazepines were found to be effective in the treatment of alcohol withdrawal, seizures and delirium tremens prevention ${ }^{59-61}$. The existence of a direct antidote for benzodiazepines favors them as a drug of choice ${ }^{62}$.

Chlordiazepoxide in a fixed dosage (FD) schedule with gradual reduction in 8-10 days is one of the most commonly used drugs for alcohol withdrawal treatment ${ }^{8}$. In inpatients, some authors prefer the so-called symptomtriggered (ST) schedule to FD with a maximum loading dose of up to $30 \mathrm{mg}$ of diazepam equivalent, or a frontloading regimen comprising an initial high dose followed by ST or FD (ref. ${ }^{11,63-65}$ ). However, there is a suggestion that even in outpatients, this regimen may help to motivate the patients to start their dependence treatment ${ }^{60,61}$. In a study of 165 patients, the quantity of medication, relapse time in the following 12 months, well-being or treatment satisfaction did not significantly differ in a group of patients treated with FD and those with an ST approach ${ }^{8}$. A recent prospective, randomized clinical trial reported no significant difference between loading or ST regimens of benzodiazepine administration in alcohol withdrawal management ${ }^{66}$. Some authors recommend ST under 24-h medical monitoring or ICU observation ${ }^{54,64}$.

\section{Eliminating and correcting somatic complications}

Early supplementation with vitamins (especially B1), glucose and fluids with electrolytes (magnesium, potassium) is vital in delirium tremens ${ }^{32,33,67-69}$. When pure glucose is administered, severe cardiomyopathy or Wernicke's encephalopathy develop quickly due to the utilization of the last thiamine reserves in activated glycolysis. High doses (300-500 mg/day) of thiamine should be administered together with or prior to glucose and should not be discontinued for 7-14 days (better administered parenterally because of reduced ability to be absorbed in an oral form) (ref. ${ }^{54,70,71}$ ).

\section{Caring for the overall physical condition}

Many factors can significantly affect the outcome, development and course of delirium. These are especially patient monitoring, safety, balanced homeostasis (hydration, nutrition), vital function support, prevention of urine and fecal retention, early mobilization, stabilization of chronic illnesses (hepataic, coagulation, anemia).

\section{Adjusting environmental conditions}

Environmental factors can influence the overall condition and should contribute to the patient's calming down. The general rules are as follows: quiet and caring environment, preferably a single room or adequate bed distance, no unnecessary objects, checks ups at least four times per hour with attempts to reorient the patient and minimization of outside noise. In case of extreme agitation or aggression, mechanical restrains may be applied for as short as possible and under close monitoring to prevent harm to the self/others ${ }^{32,33,67}$. A watchful and sensitive approach of the nursing personnel is absolutely important. 


\section{Symptomatic and supportive treatment}

Drug doses should be as low as possible to achieve the proper effect and tranquilization and should be distributed in intermittent boluses with focus on the rapid onset and its adjustment to the general condition. Premature discontinuation of the medication may result in delirium relapse in the next $24 \mathrm{~h}$. The whole treatment with gradual reduction of the medication usually takes 7-14 days.

In symptomatic therapy, benzodiazepines are the drugs of choice; in some regions, clomethiazole is used as well ${ }^{72-78}$. In alcohol withdrawal delirium, supportive therapy is essential as well.

There is cross-tolerance of alcohol and medication commonly used in the treatment of alcohol withdrawal ${ }^{11}$. In mild or moderate symptoms of alcohol withdrawal, carbamazepine may be used as an alternative drug but its use in withdrawal delirium has not been sufficiently proved $^{75}$. Under certain conditions, other additional drugs may be used together with benzodiazepines, for example antipsychotics (haloperidol, beta-blockers, clonidine or phenytoin) (ref. ${ }^{79}$ ). In case of refractory delirium, propofol has also been recently shown to be an effective adjunctive drug ${ }^{80-83}$.

\section{Subsequent care}

After delirium subsides, there is a great need of proper education and supportive psychotherapy for the patients and their families consisting of gentle explanation of the underlying causes, withdrawal and delirious phenomena or bizarre experiences. The therapist aims to get the patient's full understanding of delirious symptoms, to prevent shame, guilt or depreciation and to help with reintegration into their original environment. Subsequent care may have a great influence on the patient's motivation to commence the long-term and complex treatment of alcohol dependence and has an impact on further adherence.

\section{Clomethiazole}

The GABA-ergic model of alcohol withdrawal and withdrawal delirium favors benzodiazepines in the treatment. For adequate alleviation of delirious symptoms, four to six $300 \mathrm{mg}$ clomethiazole capsules are administered initially and according to the current condition the dose is repeated every $2-3 \mathrm{~h}$ until the calming effect is achieved, with the maximum dose being 24 capsules per day. The parenteral form of clomethiazole is no longer available on the market because of many deaths due to inappropriate use, insufficient monitoring of patients or other fatal respiratory complications ${ }^{84,85}$. If delirious patients are managed at ICUs where continuous vital function monitoring is available, clomethiazole doses may be increased to $7.2 \mathrm{~g}$ (12 g) (ref. $\left.{ }^{32,33}\right)$. As in benzodiazepines, CNS respiratory center depression may emerge when clomethiazole is used. Additionally, there is a risk of pneumonia due to bronchial secretion accumulation. Since clomethiazole is potentially addictive, it should not be administered for more than 10 days ${ }^{67,68}$. The administration of both clomethiazole and benzodiazepines must be short-term, with gradual dose reduction after a steady state is achieved; in benzodiazepines, approximately to $15-20 \%$ of the total dose a day ${ }^{36}$.

Some studies comparing clomethiazole with benzodiazepines showed its effectiveness and some of them reported shortening and generally better tolerance of treatment as well ${ }^{69,86,87}$.

\section{Benzodiazepines}

The most frequently used drugs in delirium tremens management are benzodiazepines. Usually, short-acting agents are preferred (e.g. lorazepam, midazolam and oxazepam). In clinical practice, diazepam, clonazepam or chlordiazepoxide are used as well. Oxazepam and lorazepam should be preferred as drugs of choice because of their advantageous pharmacokinetics and dynamics (no active metabolites, favorable liver metabolization by conjugation/glucuronidation). Benzodiazepines (especially clonazepam and diazepam) are also beneficial in epileptic seizure management as epileptic activity is a frequent complication seen in alcohol withdrawal and withdrawal delirium (up to $30 \%$ ). They are also the drugs of choice in sedative and hypnotic withdrawal deliria.

The dosage of benzodiazepines is supramaximal in delirium tremens or withdrawal state, comparing to their common use in anxiolytic or other indications (60-90 mg of diazepam equivalent a day) (ref.32). When administered intravenously, the risk of respiratory depression is imminent and the patient should be managed at the ICU (ref. ${ }^{69}$ ).

Temporarily, administration of midazolam in a continuous infusion is considered to be suitable in intensive care.

Potential complications of benzodiazepine therapy require increased vigilance of the involved clinicians. As short-acting benzodiazepines such as oxazepam or lorazepam are used in ST regimens according to the severity of withdrawal symptoms, the nursing personnel and clinicians trained in intensive care are needed to recognize potential complications (e.g. infection) or other changes in patients' condition, which may mimic or blunt withdrawal syndrome features. Long-acting benzodiazepines (i.e. diazepam, chlordiazepoxide) are commonly administered in FD regimens ${ }^{88}$. The peril of the FD approach is seen in under- or overestimation of the total dose resulting in excessive sedation or, oppositely, loss of control of withdrawal symptoms. Additionally, in patients who are still alcohol intoxicated, unpredictable interactions with benzodiazepines (somnolence, respiratory depression or arrest and death) may emerge. That is why in such cases, continuous and careful monitoring of their condition is necessary ${ }^{89}$.

Potential risk of abuse and addiction must be taken into consideration anytime benzodiazepines are used in withdrawal management in outpatient settings ${ }^{90}$.

\section{Antipsychotics}

Tiapride, an atypical D2/D3 antipsychotic agent, can be used in uncomplicated alcohol withdrawal syndrome. It is safe, with a wide therapeutic range - the doses can 
vary from 300 to $1800 \mathrm{mg} /$ day - and both oral and parenteral ways of administration. The total daily dose should be administered in at least 3-4 doses. It should not be used in patients with an increased risk of epilepsy because of its potential to lower the seizure threshold ${ }^{91,92}$.

In delirium tremens, tiapride alone has not shown to be effective enough so its use should be limited to uncomplicated withdrawal ${ }^{93}$.

Antipsychotics in delirium tremens should be used as augmentation in extremely agitated or aggressive patients, always in combination with benzodiazepines - the GABAergic agents are preferred. Haloperidol may be added to the medication in doses of 5-15 $\mathrm{mg}$ a day. Since there is a risk of arrhythmia due to the QT interval prolongation together with hypokalemia and seizure threshold lowering, that the patient should be monitored at the ICU (ref. ${ }^{11,94}$ ). The of haloperidol increases mortality rate.

\section{Antiepileptics}

The anticonvulsants of non-benzodiazepine type carbamazepine and oxcarbazepine with likely GABA-ergic and NMDA-blocking activity represent other drugs of possible use $\mathrm{e}^{87,95,96}$. Carbamazepine has been used for over 30 years to treat alcohol withdrawal as a non-addictive, nonsedating agent reducing alcohol withdrawal symptoms ${ }^{52,87}$. The newer anticonvulsant oxcarbazepine, a structurally modified carbamazepine, does not carry carbamazepine's side-effects of active metabolites.

A number of studies have confirmed carbamazepine efficacy in reducing symptoms of alcohol withdrawal syndrome in the inpatient setting ${ }^{72,97-102}$. Compared with benzodiazepines or clomethiazole, carbamazepine was found effective in alcohol detoxification in seven randomized controlled studies ${ }^{72,90,97-101}$. The focus was mainly on alcohol withdrawal features, delirium and seizures occurrence or presence of two or all three of them together. Six of those studies demonstrated significant alleviation in clinician-rated withdrawal phenomena using fixed or tapered (over 5-9 days) regimen with $800 \mathrm{mg}$ daily as an initial dose.

In four out of seven randomized controlled studies comparing the efficacy of carbamazepine and benzodiazepines in alcohol withdrawal, the frequency of seizures and delirium tremens was reported with the odds ratio for delirium $[\mathrm{OR}=1.25(95 \% \mathrm{CI}=0.28-5.64), P=\mathrm{NS}]$ and seizures $[\mathrm{OR}=0.93(93 \% \mathrm{CI}=0.06-14.97), P=\mathrm{NS}]$, thus showing no significant difference.

On the other hand, there are four randomized controlled trials of alcohol withdrawal management showing no effect of either oxcarbazepine or carbamazepine $^{72,101,103,104}$.

According to inpatient trials of clinician-rated symptoms, there is efficacy of carbamazepine in alcohol withdrawal treatment. However, due to a small sample size in comparative trials, the ability of carbamazepine to prevent delirium tremens or withdrawal seizures compared to benzodiazepines is questionable ${ }^{105}$. In Barrons and Roberts's opinion, carbamazepine is effective in secondary measures of alcohol withdrawal (i.e. craving and quality of sleep) reduction and is well tolerated when used in doses of $800 \mathrm{mg}$ a day in both fixed and tapered regimens. The probable explanations for studies failing to prove the therapeutic efficacy are delayed administration of the drug, underenrollment, low dosages and a bias in outcome assessment. Due to inconsistent outcomes in two studies, the benefit of oxcarbazepine in alcohol withdrawal remains undefined. However, carbamazepine showed its effect in reduction of moderate to severe withdrawal syndrome in inpatients. Benzodiazepines should remain the drugs of first choice in severe alcohol withdrawal state.

There are studies showing the efficacy of sodium valproate in alcohol withdrawal its use is discouraged in more severe cases ${ }^{106-108}$.

There is an open trial of gabapentin, a GABA-ergic anticonvulsant, in the treatment of acute alcohol withdrawal but not delirium tremens itself, showing its effectiveness in reducing mild symptoms ${ }^{109}$.

Despite the fact that other antiepileptic drugs such as topiramate and lamotrigine 110-112 $^{11}$ ay be successfully used in alcohol withdrawal management, there is not enough reliable evidence for their use in alcohol withdrawal delirium.

\section{Propofol}

Propofol, as a short-acting general anesthetic having good sedative and amnesic effects and a short half-time without any accumulation in the body tissues, may be administered continuously or in boluses. Apart from being beneficial in short-term anesthesia, it may be used as another possible medication in delirium tremens management in refractory cases ${ }^{36}$. Due to the general anesthetic effect, its use is strictly limited to the ICU settings. However, it has shown to be effective in extremely agitated delirium unresponsive to high doses of benzodiazepines in several cases ${ }^{83}$. The efficiency of propofol in alcohol withdrawal delirium is most likely due to enhancing GABA-ergic activity and NMDA receptor inhibition in the CNS (ref. ${ }^{113}$ ), which is in accordance with the GABA and glutamate hypothesis of delirium tremens.

\section{Other drugs}

The effectiveness of barbiturates was reported in cases of alcohol withdrawal delirium not responding to benzodiazepines $^{36}$. Recently, there were no significant differences found concerning the duration of delirium tremens, length of hospitalization or medical complications between phenobarbital and diazepam. Escalating bolus doses of diazepam and additional barbiturates, if necessary, reduced the need for mechanical ventilation and ICU length of stay and nosocomial infection development ${ }^{114,115}$. There are case reports showing baclofen, a GABA-B agonist, to be effective in alcohol withdrawal delirium ${ }^{116,117}$, but there is not enough evidence for its safe use in uncomplicated withdrawal ${ }^{118}$. The new $\alpha 2$ agonist dexmedetomidine was successfully used as an adjunct to benzodiazepines in 18 and 20 ICU patients diagnosed with alcohol withdrawal delirium $^{119,120}$.

The use of these drugs is limited to case studies and cannot be routinely recommended in the treatment of alcohol withdrawal delirium. 


\section{Nursing care for patients with delirium tremens}

The management of delirious patients is extremely challenging for the nursing personnel as those individuals need full-time observation in order to monitor changes in their mental condition and to prevent exhaustion, dehydration, bed sores, stools and urine retention. Patients suffering from delirium tremens are usually males in their mid-forties or fifties, meaning that they are still physically fit and strong enough to cause complications when agitated or aggressive. The assistance of hospital security guard and even mechanical restrains is therefore often needed to prevent self-harm or injuries to the staff and other patients.

\section{CONCLUSIONS}

Delirium tremens is the most severe complication of alcohol withdrawal which usually appears after longer periods of heavy drinking. This severe condition may be life-threatening and may lead to death or severe morbidity when not managed properly. The most important issue of the treatment is its prevention by early recognition of the potential risk of alcohol withdrawal and its management. When fully developed, delirium tremens is better managed at the ICU or other wards capable of monitoring the vital functions and laboratory parameters of the patients. The most effective drugs used are short-acting benzodiazepines in supramaximal doses with their sequential reduction after pacification and overall calming is achieved.

\section{ACKNOWLEDGEMENT}

Authorship contributions: BM, JP: manuscript writing; BM: figures; BM, JP, KL, KA, MC, RB, RH: data collection; BM, JP: data interpretation; BM, JP: final aproval.

Conflict of interest statement: The authors state that there were no conflicts of interest regarding publication of this article.

\section{REFERENCES}

1. Rehm J, Mathers C, Popova S, Thavorncharoensap M Teerawattananon Y, Patra J. Global burden of disease and injury and economic cost attributable to alcohol use and alcohol-use disorders. The Lancet 2009;373(9682):2223-33.

2. World Health Organization: Global Status Report on Alcohol 2004. WHO, 2004.

3. Rehm J, Zatonksi W, Taylor B, Anderson P. Epidemiology and alcohol policy in Europe. Addiction 2011;106(s1):11-9.

4. Rehm J, Shield KD, Gmel G, Rehm MX, Frick U. Modeling the impact of alcohol dependence on mortality burden and the effect of available treatment interventions in the European Union. European Neuropsychopharmacology 2013;2(23):89-97.

5. Bagnardi V, Rota M, Botteri E, Tramacere I, Islami F, FedirkoV, La Vecchia C. Light alcohol drinking and cancer: a meta-analysis. Annals of oncology 2013;24(2):301-8.

6. Room R, Babor T, Rehm J. Alcohol and public health. Lancet 2005;365:519-30.
7. McKeon A, Frye MA, Delanty N. The alcohol withdrawal syndrome. J Neurol Neurosurg Psychiatry 2008;79:854-62.

8. Elholm B, Larsen K, Hornnes N, Zierau F, Becker U. Alcohol withdrawal syndrome: symptom-triggered versus fixed-schedule treatment in an outpatient setting. Alcohol and Alcoholism 2011;46(3):318-23.

9. Becker HC. Kindling in alcohol withdrawal. Alcohol Health Res World 1998;22:25-33.

10. Wright T, Myrick H, Henderson S, Peters H, Malcolm R. Risk factors for delirium tremens: a retrospective chart review. Am J Addict 2006;15:213-9.

11. Mayo-Smith MF, Beecher LH, Fischer TL, Gorelick DA, Guillaume JL, Hill A. Management of alcohol withdrawal delirium: An evidencebased practice guideline. Arch Intern Med 2004;164:1405-12.

12. Berggren U, Claudia Fahlke C, Berglund KJ, Blennow K, Zetterberg $\mathrm{H}$, Balldin J. Thrombocytopenia in early alcohol withdrawal is associated with development of delirium tremens or seizures. Alcohol \& Alcoholism 2009;44(4):382-6.

13. Roche AM, Freeman T, Skinner N. From data to evidence, to action: findings from asystematic review of hospital screening studies for high risk alcohol consumption.Drug Alcohol Depend 2006;83:1-14.

14. Smoger SH, Looney SW, Blondell RD, Wieland LS, Sexton L, Rhodes SB, Swift RM Hospital Use of Ehtanol Survey (HUES): preliminary results. J Addict Dis 2002;21(2):65-73.

15. Spiegel D, Tommasello A, Solounias B, McDuff D. An evaluation of intravenous ethanol in hospitalized patients. J Subst Abuse Treat 1998;15(5):437-42.

16. Soyka M. Prevalence of alcohol-induced psychotic disorders. Eur Arch Psychiatry Clin Neurosci 2008a;258:317-8.

17. Soyka M. Prevalence of delirium tremens. Am J Addict 2008b;17:452.

18. Glass IB. Alcohol hallucinosis: a psychiatric enigma - 2. Follow-up studies. Br J Addict 1989;84:151-64.

19. Schuckit MA, Tipp JE, Reich T, Hesselbrock VM, Bucholz KK. The histories of withdrawal convulsions and delirium tremens in 1648 alcohol dependent subjects. Addiction 1995;90:1335-47.

20. Perala J, Kuoppasalmi K, Pirkola S, Harkanen T, Saarni S, TuulioHenriksson A, Viertio S, Latvala A, Koskinen S, Lonnqvist J and Suvisaari J. Alcohol-induced psychotic disorder and delirium in the general population. The British Journal of Psychiatry 2010;197:200-6.

21. Mennecier D, Thomas M, Arvers P, Corberand D, Sinayoko L, Bonnefoy $S$, Harnois F, Thiolet C. Factors predictive of complicated or severe alcohol withdrawal in alcohol dependent inpatients. Gastroenterol Clin Biol 2008;32(8-9):792-97.

22. Saitz R, O'malley SS. Pharmacotherapies for alcohol abuse. Withdrawal and treatment. Med Clin North Am 1997;81:881-907.

23. Lee $\mathrm{SH}$, Jang MK, Lee JY. Clinical predictors for delirium in alcohol dependence. J Gastroenterol Hepatol 2005;20:1833-37.

24. Shaw GK,Waller S, Latham CJ, Dunn G, Thomson AD. The detoxification experience of alcoholic in-patients and predictors of outcome. Alcohol Alcohol 1998;33:291-303.

25. Wojnar M, Bizon Z, Wasilewski D. Assessment of the role of kindling in the pathogenesis of alcohol withdrawal seizures and delirium tremens. Alcohol Clin Exp Res 1999;23(2):206-8.

26. Anton RF, Becker HC. Pharmacotherapy and pathophysiology of alcohol withdrawal. In: Kranzler HR (ed): The Pharmacology of Alcohol Abuse Handbook of Experimental Pharmacology, Berlin-Heidelberg: Springer-Verlag; 1995;315-67.

27. Becker HC, Littleton JM. The alcohol withdrawal "kindling" phenomenon: Clinical and experimental findings. Alcohol Clin Exp Res 1996;20(Supl):121A-124A1.

28. Breese GR, Overstreet DH, Knapp DJ. Conceptual framework for the etiology of alcoholism: a "kindling"/stress hypothesis. Psychopharmacology 2005;178(4):367-80.

29. Ballenger JC, Post RM. Kindling as a model for alcohol withdrawal syndromes. Br J Psychiatry 1978;133:1-14.

30. Post RM. Do the epilepsies, pain syndromes, and affective disorders share common kindling-like mechanisms? Epielpsy Research 2002;50(1-2):203-19.

31. Dodd PR, Beckman AM, Davidson MS, Wilce PA. Glutamate mediated transmission, alcohol, and alcoholism. Neurochemistry International 2000;37:509-33.

32. Praško J, Franková V, Seifertová D. Delirium. In: Seifertová D, Praško J, Höschl C (eds): Postupy v léčbě psychických poruch. Praha: Academia Medica Pragensis 2004;361-72. 
33. Seifertová D, Praško J. Delirující pacient. In: Herman E, Praško J, Seifertová D (eds): Konziliární psychiatrie. PrahaMedical Tribune 2007;204-20.

34. Hovorka J, Herman E. Psychické poruchy v neurologii. In: Bednařík J, Amber Z, Růžička E, editors. Klinická neurologie, část speciální II. Praha: Triton ČR 2010;1207-30.

35. Pompei $P$, Forman M, Rudberg M, Inouye SK, Braund V, Cassel CK. Delirium in hospitalized older persons: outcomes and predictors. J Am Geriatr Soc 1994;42:809-15.

36. Caplan JP. Diagnosis and treatment of agitation and delirium in the intensive care unit patient. In: Irwin RS \&, Rippe JM, editors. Intensive care medicine, 6 th ed. Philadelphia: Lippincott Williams \& Wilkins 2008;2287-95.

37. Caraceni A, Grassi L. Management of delirium. In: Caraceni A \& Grassi $\mathrm{L}$, editors. Delirium. Acute confusional states in palliative medicine. New York: Oxford University Press; 2003;131-57.

38. Coleman MP, Quaresma M, Berrino F, Lutz JM, De Angelis R, Capocaccia R, Baili P, Rachet B, Gatta G, Hakulinen T, Micheli A, Sant M, Weir HK, Elwood M, Tsukuma H, Koifman S, Azvedo e Silva G, Francisci S, Santaquilani M, Verdecchia A, Storm HH, Young JL, the CONCORD working group. Cancer survival in five continents: a worldwide population-based study (CONCORD). Lancet Oncol 2008;9:730-56

39. Victor M. Treatment of alcoholic intoxication and the withdrawal syndrome. Psychosom Med 1966;28:636-50.

40. Ferguson JA, Suelzer CS, Eckert GS, Zhou XH, Dittus RS. Risk factors for delirium tremens development. J Gen Intern Med 1996;11:410-4

41. Hovorka J, Mainerova B, Prasko J, Horacek R. Delirium. Act Nerv Super Rediviva 2012;54(4):180-91.

42. Myrick H, Anton RF. Clinical management of alcohol withdrawal. CNS Spectr 2000;5:22-32.

43. Palmstierna T. A model for predicting alcohol withdrawal delirium. Psychiatr Serv 2001;52:820-3.

44. Fiellin DA, O'Connor PG, Holmboe ES, Horowitz RI. Risk for delirium tremens in patients with alcohol withdrawal syndrome. Subst Abuse 2002;23:83-94.

45. Wojnar M, Bizon Z, Wasilewski D. The role of somatic disorders and physical injury in the development and course of alcohol withdrawal delirium. Alcohol Clin Exp Res 1999;23:209-13.

46. Wadstein J, Skude G. Does hypo-kalemia precede delirium tremens? Lancet1978;2:549-50.

47. Wetterling T, Kanitz RD, Veltrup C, Dreissen M. Clinical predictors of alcohol withdrawal delirium. Alcohol Clin Exp Res 1994;18:1100-2.

48. Wetterling T, Kanitz RD, Renner F, Fischer D. Does carbohydratedeficient transferrin predict the severity of alcohol withdrawal syndrome? Alcohol Clin Exp Res 1998;22:1053-6.

49. Brathen G, Bjerve KS, Brodtkorb E, Bovim G. Validity of carbohydrate deficient transferring and other markers as diagnostic aids in the detection of alcohol related seizures. J Neurol Neurosurg Psychiatry 2000;68:3428.

50. Berggren U, Fahlke C, Balldin J. Transient increase in platelet monoamine oxidase B activity during early abstinence in alcoholics: implications for research. Alcohol Alcohol 2000;35:377-80.

51. Takahashi S, Tani N, Yamane H. Monoamine oxidase activity in blood platelets in alcoholism. Folia Psychiatr Neurol Jpn 1976;30:455-62.

52. Lee JS, Lee BH, Ji H, Jang GH, Shin HE. Clinical Factors Correlated to Delirium Tremens during Acute Alcohol Withdrawal of Inpatients with Alcohol Dependence. J Korean Neuropsychiatr Assoc 2012;51(4):164-9.

53. Bleich S, Degner D, von Ahsen N, Ruther E, Kornhuber J. Plasma homocysteine is a predictor of alcohol withdrawal seizures. Neuroreport 2000;11:2749-52.

54. Koguchi K, Nakatsuji Y, Abe K, Sakoda S. Wernicke's encephalopathy after glucose infusion. Neurology 2004;62(3):512.

55. Walker B, Anderson M, Hauser L, Werchan I. Ethanol for alcohol withdrawal: The end of an era. J Trauma Acute Care Surg 2013;74(3):92631.

56. Gossop M, Keaney F, Stewart D, Marshall EJ, Strang J. A Short Alcohol Withdrawal Scale (SAWS): development and psychometric properties. Addict Biol 2002;7:37-43.

57. Malcolm R, Roberts JS, Wang W, Myrick H, Anton RF. Multiple previous detoxifications are associated with less responsive treatment and heavier drinking during an index outpatient detoxification. Alcohol 2000;22:159-64.
58. Erwin WE, Williams DB, Speir WA. Delirium tremens. South Med J 1998;91:425-32.

59. Whitfield CL, Thompson G, Lamb A, Spencer V, Pfeifer M, BrowningFerrando M. Detoxification of 1,024 alcoholic patients without psychoactive drugs. JAMA 1978;239:1409-10.

60. Holbrook AM, Crowther R, Lotter A, Cheng C, King D. Meta-analysis of benzodiazepine use in the treatment of acute alcohol withdrawal. CMAJ 1999;160:649-55.

61. Ntais C, Pakos E, Kyzas P, loannidis JP. Benzodiazepines for alcohol withdrawal. Cochrane Database Syst Rev 3: 2005; CD005063.

62. National Board of Health DcfEaHTA. Treatment of Alcohol Dependence-a Health Technology Assessment. Copenhagen: National Board of Health, Danish Centre for Evaluation and Health Technology Assessment 2008

63. Jaeger TM, Lohr RH, Pankratz VS. Symptom-triggered therapy for alcohol withdrawal syndrome in medical inpatients. Mayo Clin Proc 2001;76:695-701.

64. NICE (2010b)Alcohol Use Disorders: Diagnosis and Clinical Management of Alcohol-Related Physical Complications. Clinical Guideline 100. London: NICE

65. Daeppen JB, Gache P, Landry U, Sekera E, Schweizer V, Gloor S, Yersin B. Symptom-triggered vs fixed-schedule doses of benzodiazepine for alcohol withdrawal: a randomized treatment trial. Archives of internal medicine 2002;162(10):1117.

66. Maldonado JR, Nguyen LH, Schader EM, Brooks JO 3rd. Benzodiazepine loading versus symptom-triggered treatment of alcohol withdrawal: a prospective, randomized clinical trial. Gen Hosp Psychiatry 2012;34(6):611-7.

67. Doubek P, Hovorka J, Herman E, Nežádal T, Bajaček M, Praško J. Léčba deliria. Cesk Slov Neurol Neurochir 2006;69/102(S1):1319.

68. Doubek $P$. Jak můžeme řešit agitovanost a neklid v ambulantní psychiatrické praxi? Psychiatrie pro praxi 2004;3:139-41.

69. Havlůj J, Seifertová D, Bašný Z, Praško J, Šípek J. Intenzivní péče o život ohrožující stavy v psychiatrii, Praha, PCP, OBIS VTEl, Zprávy č. 99, 1991.

70. Thomson AD, Cook CC, Touquet R, Henry JA. Royal College of Physicians, London. The Royal College of Physicians report on alcohol: guidelines for managing Wernicke's encephalopathy in the accident and Emergency Department. Alcohol Alcohol 2002;37(6),513-21.

71. Brust JC. Ethanol. In: Experimental and Clinical Neurotoxicity. Second edn. Oxford: 2000

72. Lucht M, Kuehn KU, Armbruster J, Abraham G, Gaensicke M, Barnow $\mathrm{S}$, Tretzel $\mathrm{H}$, Freyberger HJ. Alcohol withdrawal treatment in intoxicated vs. non-intoxicated patients: a controlled open-label study with tiapride / carbamazepine, clomethiazole, and diazepam. Alcohol and Alcoholism 2003;38:168-75.

73. Leitlinien für Diagnostik und Therapie in der Neurologie; 4. überarbeitete Auflage, ISBN 978-3-13-132414-6;rev 2008. Georg Thieme Verlag Stuttgart

74. Alcohol-use disorders. Diagnosis and clinical management of alcohol-related physical complications. National Clinical Guideline Centre for Acute and Chronic Conditions - National Government Agency [Non-U.S.]. 2010 Jun. NGC:007897.

75. Soyka M, Kranzler HR, Berlund M, Gorelick D, Hesselbrock V, Johnson BA, Möller HJ, The WFSBP task force on treatment guidelines for substance use. World Federation of Societies of Biological Psychiatry (WFSBP)Guidelines for Biological Treatment of Substance Use and Related Disorders, Part 1: Alcoholism. The World Journal of Biological Psychiatry 2008;9(1):6-23.

76. Nimmerrichter AA, Walter H, Gutierrez-Lobos KE, Lesch OM. Doubleblind controlled trial of $\gamma$-hydroxybutyrate and clomethiazole in the treatment of alcohol withdrawal. Alcohol and Alcoholism 2002;37(1):67-73.

77. Raboch J, Anders M, Hellerová P, Uhlíková P. Psychiatrická společenost ČSL JEP. Česká psychiatrická společnosti o.s. Psychiatrie: Doporučené postupy psychiatrické péče III. Brno. 2010.

78. Monte R, Rabunal R, Casariego E, Lopez-Agreda H, Mateos A, Pertega S. Analysis of the factors determining survival of alcoholic withdrawal syndrome patients in a general hospital. Alcohol and alcoholism 2010;45(2),151-8.

79. Hayner CE, Wuestefeld NL, Bolton PJ. Phenobarbital treatment in a patient with resistant alcohol withdrawal syndrome. Pharmacotherapy 2009;29:875-8. 
80. McCowan C, Marik P. Refractory delirium tremens treated with propofol: A case series. Crit Care Med 2000;28:1781-4.

81. Takeshita J. Use of propofol for alcohol withdrawal delirium: A case report. J Clin Psychiatry 2004;65:134-5.

82. Lappin R. Propofol in delirium tremens. Ann Emerg Med 1998;32:271-2.

83. Mahajan, R Singh R, Bansal PD, Bala R. Use of propofol as adjuvant therapy in refractory delirium tremens. Ind Psychiatry J 2010;19(1):58-9.

84. Majumdar SK. Chlormethiazole: current status in the treatment of the acute ethanol withdrawal syndrome. Drug Alcohol Depend 1991;27:201-7.

85. Morgan MY. The management of alcohol withdrawal using chlormethiazole. Alcohol Alcohol 1995;30:771-4.

86. de Millas W, Ganzer F, Kuhn S, Haasen C. Oxazepam versus clomethiazol in alcohol withdrawal treatment. European addiction research 2010;16(4):179-84.

87. Franz M, Dlabal H, Kunz S, Ulferts J, Gruppe H, Gallhofer B. Treatment of alcohol withdrawal: tiapride and carbamazepine versus clomethiazole. European archives of psychiatry and clinical neuroscience 2001;251(4):185-92.

88. Chabria SB. Inpatient management of alcohol withdrawal: a practical approach. Signa Vitae 2008;3:24-9.

89. Spies CD, Dubisz N, Neumann T, Blum S, Müller C, Rommelspacher H, Brummer G, Specht M, Sanft C, Hannemann L, Striebel HW Schaffartzik W. Therapy of alcohol withdrawal syndrome in intensive care unit patients following trauma: results of a prospective, randomized trial. Critical Care Medicine 1996;24:414-22.

90. Malcolm R, Myrick H, Roberts J, Wang MS, Anton RF, Ballenger JC. The effects of carbamazepine and lorazepam on single versus multiple previous alcohol withdrawals in an outpatient randomized trial. Journal of General Internal Medicine 2002;17:349-55.

91. Stanley KM, Worrall Cl, Lunsford SI, Simpson KN, Miller JG, Spencer AP. Experience with an adult alcohol withdrawal syndrome practice guideline in internal medicine patients. Pharmacotherapy 2005;25(8):1073-83.

92. Bayard M, McIntyre J, Hill KR, Woodside J. Alcohol withdrawal syndrome. Am Fam Physician 2004;69(6):1443-550.

93. Martinotti G, Di Nicola M, Frustaci A, Romanelli R, Tadeschi D, Guglielmo R, Guerriero L, Bruschi A, De Filippis, Pozzi G, Di Giannantonio M, Bria P, Janiri L. Pregabalin, tiapride and lorazepam in alcohol withdrawal syndrome: a multi-centre, randomized, single-blind comparison trial. Addiction 2010;105(2):288-99.

94. Baldessarini RJ, Tarazi FI. Drugs and the treatment of psychiatric disorders. In: Hardman JG, Limbard LE, Gilman AG, eds: The Pharmacological Basis of Therapeutics. New York, NY: McGraw-Hill, 2001:485-520.

95. Stepanovic-Petrovic RM, Tomić MA, Vućković SM, Kocev N, Ugresi ND, Prostran M, Boskovi B. GABAergic mechanisms are involved in the antihyperalgesic effects of carbamazepine and oxcarbazepine in a rat model of inflammatory hyperalgesia. Pharmacology. International Journal of Experimental and Clinical Pharmacology 2008; 53-8. doi: $10.1159 / 000127841$

96. Hough CJ, Irwin RP, Gao XM, Chuang DM. Carbamazepine inhibition of $\mathrm{N}$-methyl-D-aspartate evoked calcium influx in rat cerebellar granule cells. Journal of Pharmacology 1996;276:143-9.

97. Kalyoncu OA, Beyazyurek M, Kuru L, Yazman U. Double-blind comparative trial with carbamazepine vs. diazepam treatment of alcohol withdrawal. European neuropsychopharmacology: The journal of the European College of Neuropsychopharmacology 1996;6(Suppl. 3):1-2.

98. Stuppaeck $\mathrm{CH}$, Pycha R, Miller $\mathrm{C}$, Whitworth $\mathrm{AB}$, Oberbauer $\mathrm{H}$, Fleischhacker WW. Carbamazepine vs. oxazepam in the treatment of alcohol withdrawal: a double-blind study. Alcohol and Alcoholism 1992;27:153-8.

99. Malcolm R, Ballenger JC, Sturgis ET, Anton R. Double-blind controlled trial comparing carbamazepine to oxazepam treatment of alcohol withdrawal. American Journal of Psychiatry 1989;146:61721.
100. Ritola E, Malinen L. A double-blind comparison of carbamazepine and clomethiazole in the treatment of alcohol withdrawal syndrome. Acta Psychiatrica Scandinavica 1981;64:254-9.

101. Hillbom M, Tokola R, Kuusela V, Karkkainen P, Kalli-Lemma L, Pilke A, Kaste M. Prevention of alcohol withdrawal seizures with carbamazepine and valproic acid. Alcohol 1989;6:223-6.

102. Bjorkqvist SE, Isohanni M, Mäkelä R, Malinen L. Ambulant treatment of alcohol withdrawal symptoms with carbamazepine: a formal multicentre double-blind comparison with placebo. Acta Psychiatrica Scandinavica 1976;53:333-42.

103. Schik G, Wedegaertner FR, Liersch J, Hoy L, Emrich HM, Schneider U. Oxcarbazepine vs. carbamazepine in the treatment of alcohol withdrawal. Addiction Biology 2005;10:283-8.

104. Koethe D, Juelicher A, Nolden BM, Braunwarth WD, Klosterkotter J, Niklewski G. Oxcarbazepine-efficacy and tolerability during treatment of alcohol withdrawal: a double-blind, randomized, placebo-controlled multicenter pilot study. Alcoholism, Clinical and Experimental Research 2007;31:1188-94.

105. Barrons R, Roberts N. The role of carbamazepine and oxcarbazepine in alcohol withdrawal syndrome. Journal of Clinical Pharmacy and Therapeutics 2010;35:153-67.

106. Longo LP, Campbell T, Hubatch S. Divalproex sodium (Depakote) for alcohol withdrawal and relapse prevention. Journal of addictive diseases 2002;21(2):55-64.

107. Rosenthal RN, Perkel C, Singh P, Anand O, Miner CR. A pilot open randomized trial of valproate and phenobarbital in the treatment of acute alcohol withdrawal. The American Journal on Addictions 1998;7(3):189-97.

108. Lum E, Gorman SK, Slavik RS. Valproic acid management of acute alcohol withdrawal. The Annals of pharmacotherapy 2006;40(3):4418.

109. Bonnet U, Hamzavi-Abedi R, Specka M, Wiltfang J, Lieb B, Scherbaum $\mathrm{N}$. An open trial of gabapentin in acute alcohol withdrawal using an oral loading protocol. Alcohol Alcohol 2010;45(2):143-5.

110. Rustembegovic A, Sofic E, Kroyer G. A pilot study of topiramate (Topamax) in the treatment of tonic-clonic seizures of alcohol withdrawal syndromes. Med Arh 2002;56:211-2.

111. Choi EA, Ki SW, Kim SE, Kim JW, Park JK. The efficacy and safety of topiramate in the treatment of alcohol withdrawal. J Korean Neuropsychiatr Assoc 2005;44:328-33.

112. Krupitsky EM, Rudenko AA, Burakov AM, Slavina TY, Grinenko AA, Pittman B, Gueorguieva R, Petrakis IL, Zvartau EE, Krystal JH. Antiglutamatergic strategies for ethanol detoxification: comparison with placebo and diazepam. Alcohol Clin Exp Res 2007;31:604-11.

113. Marik PE. Propofol: Therapeutic Indications and Side-Effects. Current Pharmaceutical Design 2004;10(29):3639-49.

114. Michaelsen IH, Anderson JE, Fink-Jensen A, Allerup P, Ulrichsen J. Phenobarbital versus diazepam for delirium tremens - a retrospective study. Dan Med Bul 2010;57(8):A4169.

115. Gold JA, Rimal B, Nolan A, Nelson LS. A strategy of escalating doses of benzodiazepines and phenobarbital administration reduces the need for mechanical ventilation in delirium tremens. Critical Care Medicine 2007;35(3):724-30.

116. Addolorato G, Leggie L, Abenavoli L, DeLorenzi G, Parente A, Caputo F, Janini L, Capristo E, Rapaccini GL, Gasabarrini G. Suppression of Alcohol Delirium Tremens by Baclofen Administration: A Case Report. Clinical Neuropharmacology 2003;26(5):258-62.

117. Addolorato G, Leggio L, Abenavoli L, Agabio R, Caputo F, Capristo E, Colombo G, Gessa GL, Gasbarrini G. Baclofen in the Treatment of Alcohol Withdrawal Syndrome: A Comparative Study vs Diazepam. The American Journal of Medicine 2006;119:276.e13-276.e18.

118. Liu J, Wang L. Baclofen for alcohol withdrawal. Cochrane Database of Systematic Reviews 2011, Issue 1. Art. No.: CD008502.

119. Talonen J, Rossinen J, Alho H, Harjola VP. Dexmedetomidine in addition to benzodiazepine-based sedation in patients with alcohol withdrawal delirium. Eur J Emerg Med 2013;20(6):425-7.

120. Rayner SG, Weinert CR, Peng H, Jepsen S, Broccard AF, Study Institution. Dexmedetomidine as adjunct treatment for severe alcohol withdrawal in the ICU. Ann Intensive Care 2012;2(1):12. 